Dr Slobodan Janićijević, pukovnik, dipl. inž. VP 9513, Beograd

\section{ODREĐIVANJE OPTIMALNE ARHITEKTURE INERCIJALNOG MERNOG BLOKA SA STANOVIŠTA POGODNOSTI DETEKCIJE OTKAZA SENZORA}

UDC: $629.7 .052: 527: 681.586$

Rezime:

$U$ ovom članku analitički je ispitano 11 raznih rezervisanih arhitektura inercijalnog mernog bloka (IMB), sa stanovišta pogodnosti za detekciju senzora koji daju netačne parametre ili su potpuno otkazali. Algoritam ispitivanja baziran je na jednačinama parnosti i teoriji najmanjeg kvadrata greške rezervisanih senzora. ${ }^{l}$ Određena je optimalna arhitektura IMB sa stanovišta pogodnosti za detekciju otkaza senzora.

Ključne reči: besplatformski inercijalni navigacijski sistem, inercijalni merni blok, rezervisana arhitektura senzora, detekcija otkaza, jednačine parnosti.

\title{
DETERMINING OPTIMUM INERTIAL MEASUREMENT UNIT ARCHITECTURE FROM THE VIEW-POINT OF SENSOR FAULT DETECTION
}

Summary:

This paper analytically analized 11 redundant architectures of the inertial measurement unit (IMU) from the view-point of detection capability of sensors which give inaccurate parameters or which failed completely. The test algorithm is based on parity equations and the least square error theory of redundant sensors. At the end of the paper an optimum architecture of the inertial measurement unit from the view-point of sensor fault detection capability was proposed.

Key words: Strapdown inertial navigation system, inertial measurement unit, redundant sensor architecture, fault detection, parityequations.

\section{Uvod}

U mnogim kritičnim i važnim vazduhoplovnim zadacima zahteva se velika pouzdanost rada ključnih sistema vazduhoplova, među koje spada i inerci-

U teoriji mernih sistema do sada su primenjene sledeće metode (algoritmi) za detekciju neispravnih senzora: adaptivna metoda, sekvencijalna metoda na bazi Kalmanovog filtra, metoda praga, metoda kvadrata greške, Bajesova metoda, metoda maksimalne verodostojnosti, minimaksna metoda, metoda srednje vrednosti (bez praga), analitička metoda i metoda na bazi teorije Markovca. Učinak svake od nabrojanih metoda zavisi od arhitekture, odnosno tipa rezervisanja IMB. jalni navigacijski sistem (INS), jer daje osnovne navigacijske parametre aviona (poziciju, brzinu, uglovnu brzinu, linearno ubrzanje i dr.), i drugi uređaji, kao što su: radar, autopilot, FLIR, itd. ${ }^{2}$ Glavni razlog relativno male pouzdanosti prvih

${ }^{2}$ Prvi INS su bili platformskog tipa sa kardanskim ramovima. Pojavom ,suvih“", laserskih i fiberoptičkih žiroskopa brzih avionskih procesora u MIL standardu, algoritmi na bazi kvaterniona mogli su da se primene, tako da su se krajem sedamdesetih godina prošlog veka pojavili prvi besplatformski INS (BINS) sa osnovnom osobinom da su im senzori (žiroskopi i akcelerometri) čvrsto vezani za avion i usmereni u pravcu osa aviona. 
BINS (oko stotinu časova) bio je mala pouzdanost njegovog ključnog dela IMB, koji se sastoji od senzora, žiroskopa i akcelerometara.

Pouzdanost navigacijskih parametara, koje su ,potrošači“ dobijali od BINS, u prvo vreme povećala se uvođenjem rezervisanja čitavog sistema BINS. Naime, dva ili tri BINS radila su u paralelnoj vezi, pri čemu je jedan - osnovni BINS stalno radio, a preostali su bili u rezervi (u radnoaktivnom stanju, stand by režimu ili su se uključivali ako osnovni BINS otkaže ${ }^{3}$ ). Međutim, ovaj način povećanja pouzdanosti rada zahteva višestruko veći prostor za ugradnju BINS u avionu, ima veću masu i cenu.

Napretkom tehnologije, već sredinom sedamdesetih godina XX veka, vodeći proizvođači BINS u svetu (Honeywell i Litton) sačinili su „klaster“4 inercijalnih senzora, koji su činili jedan rezervisani sistem. Intenzivno su ispitivane razne arhitekture IMB, tj. klasteri, na bazi rezervisanja senzora (simetrične, ortogonalne i koplanarne) primarno, radi veće pouzdanosti BINS, koja je u uskoj vezi sa boljom detekcijom neispravnih senzora u IMB, a sekundarno radi bolje tačnosti izračunavanja navigacijskih parametara, manje mase i dimenzije IMB.

U ovom članku analizirano je 11 rezervisanih arhitektura IMB sa stanovišta pogodnosti za detekciju senzora koji daju netačne parametre ili su potpuno otkazali, tj. prestali sa radom. Algoritam izložen $u$

\footnotetext{
U kosmičkim letelicama tipa Shuttle ugrađena su tri rezervisana BINS

${ }^{4}$ „Klaster“ sadrži nekoliko žiroskopa u jednom kućištu. Na primer, „klaster“ sa laserskim žiroskopima može da sadrži i do 6 žiroskopa, dok je sa ,suvim“ - DTG (dry tuned gyro) žiroskopima napravljen „klaster“ sa dva žiroskopa, tj. TDOF (two degree of freedom) žiroskop.
}

članku baziran je na jednačinama parnosti i teoriji najmanjeg kvadrata greške.

\section{Jednačine i vektor parnosti}

Iz teorije mernih sistema poznato je da se u slučaju $n$ rezervisanih senzora može formirati $n$ jednačina merenja, tj.:

$m=H x+\varepsilon$

gde je:

$m$ - vektor merenja (npr: $m_{i}-$ mereni parametar iz $i$-tog senzora),

$x$ - trodimenzionalni vektor stanja (uglovna brzina ili linearno ubrzanje), npr. u pravcu ortogonalnih osa koordinatnog sistema aviona,

$\varepsilon$ - $n$-dimenzionalni vektor šuma sa Gausovom raspodelom,

$H$ - matrica merenja ili matrica geometrije senzora. Rang matrice $H$ jednak je dimenziji (obično je 3 ) vektora $x$.

Kada se trodimenzionalni vektor $x$ meri skupom od $n$ rezervisanih senzora, koji daju na svom izlazu parametar $m_{n}$ bez šuma, onda se može pokazati da je [1]:

$\lambda_{1} m_{1}+\lambda_{2} m_{2}+\ldots+\lambda_{n} m_{n}=0$

gde je $\lambda_{n}$ skalar.

Kada merenje $m_{n}$ sadrži grešku $\varepsilon_{n}$, jednačina (2) glasi [1]:

$\lambda_{1}\left(m_{1}-\varepsilon_{1}\right)+\lambda_{2}\left(m_{2}-\varepsilon_{2}\right)+\ldots+$

$+\lambda_{n}\left(m_{n}-\varepsilon_{n}\right)=0$

ili $\lambda_{1} m_{1}+\lambda_{2} m_{2}+\ldots+\lambda_{n} m_{n}=\eta$

gde je $\eta$ vektor „nedoslednosti“ ili grešaka pri merenju [1]. 
Jednačina (4) naziva se jednačina parnosti. Ukoliko se merenje $n_{0}$ dimenzionalnog vektora obavlja sa $n$ senzora $\left(n>n_{0}\right)$, onda postoji $C_{4}^{n}=\frac{n !}{4 !(n-4) !}$ jednačina parnosti, od kojih su $q=n-n_{0}$ nezavisne.

Pošto postoji $q$ nezavisnih jednačina parnosti onda se vektor nedoslednosti $\eta$ može izraziti preko q nezavisnih promenljivih $p_{1}, p_{2}, \ldots, p_{q}$. Vektor $p$ naziva se vektor parnosti a $q$ dimenzionalni prostor parnosti.

S druge strane, vektor $\eta$ može se izraziti preko mernog vektora $m$, tako da je:

$$
\eta=v_{n}^{T} m
$$

gde je $v_{n}^{T}$ unapred definisan $n \times 1$ dimenzionalni vektor, čije pojedine komponente mogu imati vrednost nula.

Jednačina parnosti $p_{n}$ je linearna kombinacija izlaza $m_{i}$ iz senzora, i nezavisna je od stvarne vrednosti vektora $x$, $\mathrm{tj}$. :

$$
p_{n}=v_{n}^{T} m
$$

Da bi se formirao vektor $p$, uvodi se matrica $V$, dimenzije $q \times n$, čiji su redovi bilo koji $q$ linearno nezavisni nula vektori matrice $H^{T}$. Tada je:

$p=V m$

Jedan od načina za određivanje koeficijenata matrice $V$ dat je u [1], gde koeficijenti matrice $V$ treba da zadovolje sledeće uslove:

$$
\begin{aligned}
& V H=0 \\
& V V^{T}=I \\
& V^{T} V=I-H\left(H^{T} H\right)^{-1} H^{T}=W
\end{aligned}
$$

Koeficijenti matrice $V$ određuju se na osnovu sledećih jednačina [1]:
$V_{11}^{2}=W_{11}, V_{i j}=0, j<i, V_{l j}=\frac{W_{l j}}{V_{11}}, j=2, \ldots, n$

$V_{i i}^{2}=W_{11}-\sum_{k=1}^{i-1} V_{k i}^{2}, i=2, \ldots, q$

$V_{i j}=\frac{\left(W_{i j}-\sum_{k=1}^{i-1} V_{k i} V_{l j}\right)}{V_{i i}}, i=2, \ldots, n, j=i+1, \ldots, n$

Drugi način određivanja koeficijenata vektora $v_{n}$ je prema broju $k$ koeficijenata vektora $v_{n}$ koji nemaju vrednost nula. Može se pokazati da ako tri senzora nisu koplanarna, onda mora biti $k \geq 4$, a ako su koplanarna $k=3$. Ako su dva senzora kolinearna postoji jednačina parnosti kod koje je $k=2$. Za $k \leq 4$ može se uzeti da je $\left\|v_{n}\right\|^{2}=1$, odnosno zbir kvadrata apsolutnih vrednosti bilo kog reda $n$ matrice $V$ jednak je jedan.

Zamenom (2) u (5), jednačina (5) postaje:

$$
p=v_{n}^{T} \varepsilon
$$

gde je $\varepsilon$ šum sa Gausovom raspodelom:

$$
\varepsilon \sim N\left(0, \sigma^{2} I_{n}\right)
$$

U slučaju da nema otkaza senzora, jednačina parnosti (9) ima sledeće statističke parametre (srednju vrednost i varijansu):

$E(p)=0 ; \sigma_{p}^{2}=v_{n}^{T} v_{n} \sigma^{2}$

U slučaju neispravnosti $j$-tog senzora, pretpostaviće se da će se izlaz $m_{j}$ povećati za konstantnu vrednost $b_{j}, \mathrm{tj}$.:

$m_{j}=h_{j}^{T} x+b_{j} \varepsilon_{j}$ 
tako da jednačina parnosti (9) ima sledeće statističke parametre:

$$
E(p)=v_{j} b_{j} ; \quad \sigma_{p}^{2}=v_{n}^{T} v_{n} \sigma^{2}
$$

Iz jednačine (6) vidi se da se na osnovu samo jedne jednačine parnosti može detektovati neispravan senzor, ali ne i da se izoluje. Dovoljan broj jednačina parnosti koje potpuno detektuju i izoluju neispravan senzor zavisi od arhitekture IMB.

$\mathrm{Za}$ arhitekturu IMB, kod koje dve merne ose senzora nisu kolinearne, skup od tri jednačine parnosti je dovoljan da se detektuje otkaz prvog senzora. Broj koeficijenata čija vrednost nije nula jednaka je ili veća od 4.

$\mathrm{Za}$ arhitekturu IMB kod koje su dve ili više mernih osa senzora kolinearne, ili su tri ili više mernih osa senzora koplanarne, skup od tri jednačine parnosti nije dovoljan za detekciju i izolaciju otkaza prvog senzora.

\section{Algoritmi \\ Algoritam sa minimalnim brojem jednačina parnosti}

Da bi se neispravan senzor izolovao potrebno je formirati $r \times 1$-dimenzionalni vektor jednačina parnosti $p_{r}$, pri čemu je $r \leq n-3$, gde je $n$ maksimalan broj jednačina parnosti, tako da je:

$p_{r}=V m$

Dakle, treba odrediti minimalan broj $r$ jednačina parnosti $p_{r}$ na osnovu kojih se može detektovati neispravan senzor. Logički vektor $q_{r}$, koji se može izvesti iz vektora parnosti $p_{r}$, treba da zadovolji sledeće uslove za detekciju otkaza senzora:

$q_{1}= \begin{cases}0, & p_{i} \leq T_{i} \\ 1, & p_{i}>T_{i}\end{cases}$

gde je:

$q_{i}-i$-ta komponenta vektora $q_{r}$,

$T_{i}$ - prag odluke vezan za jednačinu parnosti $p_{i}$.

Koeficijenti matrice $V$ određuju se na osnovu jednačine (8). Ako svaka kolona matrice $V$ sadrži najmanje jednu komponentu čija je vrednost različita od nule, onda je jednačina (13) pogodna za ispitivanje pogodnosti - kvaliteta različitih arhitektura IMB, za pouzdano određivanje neispravnog senzora.

Ako se pretpostavi da vektor greške $\varepsilon$ ima raspodelu po zakonitosti izraza (9a), može se pokazati da je: - u slučaju nepostojanja greške senzora $\left(b_{j}=0\right)$, statistički parametri jednačine parnosti $p_{r}=V \varepsilon$ glase:

$E\left(p_{r}\right)=0 ; \quad \sigma_{p_{r}}^{2}=V V^{T} \sigma^{2}$

a gustina verovatnoće je:

$$
\begin{aligned}
& P\left(p_{r}, 0\right)=(2 \pi)^{-(r-3) / 2}\left|V V^{T} \sigma^{2}\right|^{-1 / 2} \\
& \exp \left(-\frac{1}{2} p_{r}^{T}\left(V V^{T} \sigma^{2}\right)^{-1} p_{r}\right)
\end{aligned}
$$

- u slučaju otkaza senzora $m_{j}\left(b_{j} \neq 0\right)$, statistički parametri jednačine parnosti $p_{r}=V b_{j}+V \varepsilon \mathrm{su}:$

$E\left(p_{r}\right)=v_{j} b_{j} ; \quad \sigma_{p_{r}}^{2}=V V^{T} \sigma^{2}$

gde je $v_{j} j$-ta kolona matrice $V$. 
Gustina verovatnoće je:

$$
\begin{aligned}
& P\left(p_{r}, b_{j}\right)=(2 \pi)^{-(r-3) / 2}\left|V V^{T} \sigma^{2}\right|^{-1 / 2} \\
& \exp \left(-\frac{1}{2}\left(p_{r}-v_{j} b_{j}\right)^{T}\left(V V^{T} \sigma^{2}\right)^{-1}\left(p_{r}-v_{j} b_{j}\right)\right)
\end{aligned}
$$

Uvođenjem parametra-indeksa $J_{j}$ koji predstavlja logaritamski odnos hipoteza (16) i (17) dobija se da je:

$$
J_{j}=\ln \left[\frac{P\left(p_{r}, b_{j}\right)}{P\left(p_{r}, 0\right)}\right]
$$

U [2] je pokazano da se jednačina (18) može napisati i u obliku:

$$
J_{j}=\left(v_{j} b_{j}-0\right)^{T}\left(V V^{T}\right)^{-1} \sigma^{-2}\left(v_{j} b_{j}-0\right)
$$

Poređenje neće izgubiti na opštosti ako se jednačina (19) normalizuje za $b_{j}$ i $\sigma^{2}$. Tada $J_{j}$ postaje mera kvaliteta pogodnosti arhitekture IMB za detekciju i izolaciju neispravnog senzora $m_{j}$, odnosno:

$$
J_{j}=V_{j}^{T}\left(V V^{T}\right)^{-1} v_{j}
$$

Pošto svaka arhitektura IMB sadrži $n$ rezervisanih senzora, formira se $n \times 1$ dimenzionalni vektor:

$J^{T}=\left(J_{1} J_{2} \ldots . . J_{n}\right)$

Uvodi se koeficijent $F_{d l}$, tako da je:

$$
F_{d 1}=\min _{J}\left\{J_{j}\right\}, \quad j=1,2, \ldots, n
$$

Parametar $F_{d 1}$ predstavlja brojčani pokazatelj kvaliteta svakog skupa jednačina parnosti, koja zavisi od arhitekture (tipa rezervisanja) senzora IMB i orijen- tacije mernih osa senzora $\mathrm{u}$ odnosu na merni vektor. Uočava se da je $F_{d 1}$ funkcija matrice $V$ koja je u vezi sa orijentacijom rezervisanih senzora u IMB i izborom jednačina parnosti. Minimalan broj $r$ jednačina parnosti izračunava se sabirajući jednačinu (20) po $j$, tj.:

$$
\begin{aligned}
& \sum_{j=1}^{n} J_{j}=\sum_{j=1}^{n} V_{j}^{T}\left(V V^{T}\right)^{-1} v_{j}= \\
& =\sum_{j=1}^{n} \operatorname{trag}\left[\left(V V^{T}\right)^{-1} v_{j} v_{j}^{T}\right]= \\
& =\operatorname{trag}\left[\left(V V^{T}\right)^{-1} \sum_{j=1}^{n}\left(v_{j} v_{j}^{T}\right)\right]
\end{aligned}
$$

Pošto je: $\sum_{j=1}^{n} v_{j} v_{j}^{T}=V V^{T}$

sledi da je: $\sum_{j=1}^{n} J_{j}=\operatorname{trag}\left|I_{r}\right|=r$

Jednačina (23) pokazuje da se kod proizvoljne arhitekture IMB povećava pogodnost za detekciju neispravnih senzora ako se povećava broj jednačina parnosti. Jednačina (23) takođe ukazuje da, ako je $r<n$, onda se maksimalna pogodnost za detekciju neispravnog senzora dobija ako sve komponente vektora $J$ imaju istu vrednost, $\mathrm{tj}$.:

$\max F_{d 1}=\frac{r}{n}$

\section{Algoritam sa n jednačina parnosti}

Alternativni algoritam za formiranje skupa jednačina parnosti je ako se formira jedna jednačina parnosti za svaki sen- 
zor koji može otkazati. To znači da treba formirati skup od $n$ jednačina parnosti, jer IMB sadrži $n$ senzora.

Može se pretpostaviti da se jednačina parnosti: $p_{1}=V_{1 n}^{T} m$ (25) koristiti za detekciju otkaza senzora $m_{1}$, gde je matrica $V_{1 n}^{T}$ data u obliku:

$$
V_{1 n}^{T}=\left[\begin{array}{ll}
V_{11} & V_{12} \ldots . . V_{1 n}
\end{array}\right]
$$

Koeficijente vektora $V_{1 n}^{T}$ treba tako odabrati da je jednačina parnosti $p_{1}$ što osetljivija na merenje $m_{1}$, a što neosetljivija na merenja ostalih senzora. To se može ostvariti ako se uzme da je koeficijent $V_{11}=1$ i minimizira zbir kvadrata ostalih koeficijenata, $\mathrm{tj}$.:

$$
C=\min \sum_{k=2}^{n} v_{1 k}^{2}
$$

i uz uslov ortogonalnosti matrica $H \mathrm{i} v_{1 n}, \mathrm{tj}$.:

$H^{T} v_{1 n}=0$

Ako se definiše $(n-1)$ - dimenzionalni vektor:

$v_{1(n-1)}^{T}=\left(\begin{array}{ll}v_{12} & v_{13} \ldots . . v_{1 n}\end{array}\right)$

i $3 \times(n-1)$ matricu:

$$
H_{n-1}^{T}=\left[\begin{array}{ll}
h_{2} & h_{3} \ldots . . h_{n}
\end{array}\right]
$$

gde je $h_{j}$ jedinični vektor u pravcu merne ose $j$-tog senzora, jednačina (28) može se napisati u obliku:

$$
H_{n-1}^{T} v_{1(n-1)}+h_{1} v_{11}=0
$$

tako da se problem nalaženja minimuma svodi na rešavanje linearnih jednačina:

$$
\left(\begin{array}{ll}
2 I_{(n-1)} & H_{n-1} \\
H_{n-1}^{T} & 0_{3 \times 3}^{T}
\end{array}\right)\left(\begin{array}{c}
v_{1(n-1)} \\
\Lambda
\end{array}\right)=\left(\begin{array}{c}
0_{n-1} \\
-h_{1}
\end{array}\right)
$$

gde je $\Lambda$ vektor Lagranžeovih množitelja.

Rešenje jednačine (32) je:

$$
v_{1(n-1)}=-H_{n-1}\left(H_{n-1}^{T} H_{n-1}\right)^{-1} h_{1}
$$

čime su ujedno određene i vrednosti koeficijenata $v_{1(n-1)}$ matrice $V$.

Jednačina parnosti $p_{1}$ tada glasi:

$$
p_{1}=m_{1}-h_{1}^{T}\left(H_{n-1}^{T}\right)^{-1} H_{n-1}^{T} m_{n-1}
$$

gde je $m_{n-1}^{T}=\left(\begin{array}{ll}m_{2} & m_{3} \ldots . . m_{n}\end{array}\right)$

Drugi član desne strane jednačine (34) predstavlja procenu $\hat{m}_{1}$, na osnovu metode najmanjeg kvadrata, baziranu na $(n-1)$ merenja, ali koja ne uključuju $m_{1}$, tako da se jednačina (34) može napisati kao:

$p_{1}=m_{1}-\hat{m}_{1}$

Algoritam za određivanje koeficijenata jednačine parnosti $p_{1}$, odnosno koeficijenata matrice $V_{1(n-1)}$, može se koristiti i za određivanje koeficijenata preostalih $(n-1)$ jednačina parnosti. Jednačina (36) važi i za ostale jednačine parnosti.

Ako nema otkaza senzora statistički parametri jednačina parnosti $p_{1}$ dati su kao i u jednačini (10), tj.:

$E\left(p_{i}\right)=0 ; \quad \sigma_{p i}^{2}=v_{i n}^{T} v_{i n} \sigma^{2}$ 

(12), tj.:

U slučaju otkaza važi jednačina

$E\left(p_{i}\right)=v_{i j} b_{j} ; \quad \sigma_{p i}^{2}=v_{i n}^{T} v_{i n} \sigma^{2}$

Uvođenjem parametra-indeksa $J_{i j}$, koji predstavlja logaritamski odnos hipoteza, (37) i (38) slično jednačinama (18) i (19), može se dobiti da je:

$J_{i j}=\left(v_{i n}^{T} v_{i n}\right)^{-1} v_{i j}^{2}$

odnosno:

$J_{i}^{T}=\left(\begin{array}{lll}J_{i 1} & J_{i 2} \ldots . . . \\ \text { in }\end{array}\right)$

Vektor $J_{i}^{T}$ naziva se merom kvaliteta za jednačinu parnosti $p_{i}$. Pošto se želi da pogodnost za detekciju, koja je vezana za jednačinu parnosti $p_{i}$, bude visoka za otkaze vezane za merenje $m_{i} i$-tog senzora, a niska za otkaze ostalih senzora, uvodi se brojčani pokazatelj kvaliteta:

$$
F_{d 2}^{*}=\frac{J_{i i}}{\max _{j} J_{i j}}, \quad j \neq i
$$

Brojčani pokazatelj kvaliteta pogodnosti za detekciju i izolaciju otkaza jedne arhitekture IMB pomoću skupa od $n$ jednačina parnosti biće:

$$
F_{d 2}=\min _{i}\left\{\frac{J_{i i}}{\max _{j} J_{i j}}\right\}, \quad j \neq i
$$

Kao jednačina (22) i jednačina (42) je striktno funkcija matrice $V$, tj. orijentacije i rezervisanja arhitekture IMB. U slučaju uporedne analize arhitek- tura IMB, najbolja je arhitektura koja zadovoljava uslov:

$$
F_{n a j}=\max _{1}\left\{\min _{i}\left(\frac{J_{i i}}{\max _{j} J_{i j}}\right)\right\}, \quad j \neq i
$$

\section{Praktična primena algoritma na 11 arhitektura IMB}

Vrednosti koeficijenta $J_{i}^{T}$ i brojčanog pokazatelja kvaliteta $F_{d 2}$ pogodnosti za detekciju neispravnih senzora izračunaće se za nekoliko mogućih arhitektura IMB, gde senzori mogu biti jednoosni (SDOF) i dvoosni (TDOF), koristeći metodu sa minimalnim brojem jednačina parnosti.

\section{Arhitekture IMB sa SDOF senzorima}

U slučaju arhitekture IMB u obliku pravilnog dodekaedra sa šest SDOF senzora, merne ose SDOF senzora su normalne na površine dodekaedra (slika 1). Merne ose senzora 1 i 4 su u ravni $X-Y$ i pod uglom su od $58,28^{\circ}$ u odnosu na $+X$ osu. Merna osa senzora 3 je u ravni $X-Z$ i pod uglom je od $31,72^{\circ}$ u odnosu na $+Y$ osu. Ugao između mernih osa senzora $1 \mathrm{i}$ 4,2 i 5 i 3 i 6 iznosi $63,44^{\circ}$, odnosno $\alpha=58,28^{\circ}$ i $\beta=31,72^{\circ}$. Transponovana matrica $H_{1}^{T}$ tada ima vrednost: ${ }^{5}$

$$
\begin{aligned}
H_{l}^{T}=\left[\begin{array}{cccccc}
\sin \theta & 0 & \cos \theta & -\sin \theta & 0 & \cos \theta \\
\cos \theta & \sin \theta & 0 & \cos \theta & -\sin \theta & 0 \\
0 & \cos \theta & \sin \theta & 0 & \cos \theta & -\sin \theta
\end{array}\right] \\
{ }^{5} \text { Arhitektura IMB predložena u [2]. }
\end{aligned}
$$


gde je: $\theta=\frac{1}{2} \operatorname{arctg}(2) \cong 31,71747^{\circ}$

$\sin \theta=\sin \sqrt{\frac{5-\sqrt{5}}{10}} \cong 0,526$,

$\cos \theta=\cos \sqrt{\frac{5+\sqrt{5}}{10}} \cong 0,851$

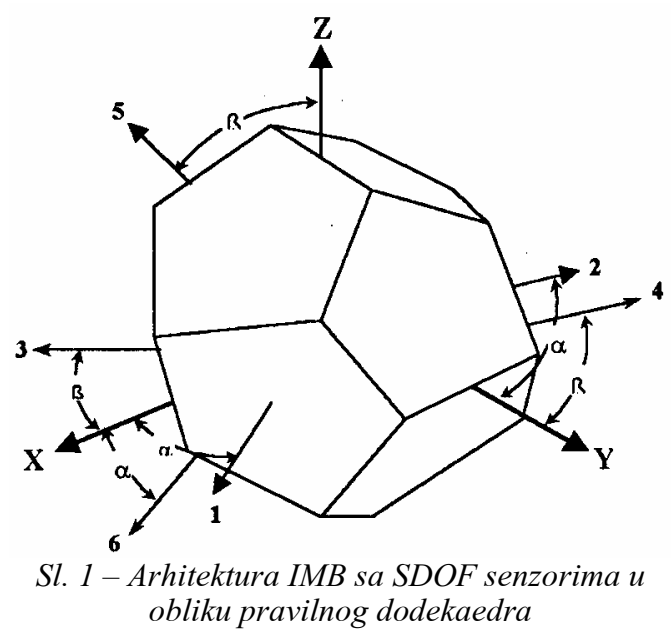

Koristeći jednačinu (8) može se pokazati da matrica $V_{1}$ ima sledeću vrednost:

$V_{1}=\left[\begin{array}{cccccc}0,709 & -0,317 & -0,317 & -0,317 & -0,317 & -0,317 \\ 0 & 0,63 & 0,196 & 0,196 & -0,51 & 0,51 \\ 0 & 0 & 0,603 & -0,603 & -0,373 & -0,372\end{array}\right]$

U slučaju orijentacije mernih osa IMB sa šest SDOF senzora u odnosu na površine pravilnog dodekaedra, pri čemu su merne ose 1. i 2. senzora u ravni $X-Z$ i pod uglom od $58,28^{\circ}$ u odnosu na $Z$ osu, merne ose 3 . i 4. senzora u ravni $X-Y$ i pod uglom $58,28^{\circ}$ u odnosu na $X$-osu i merne ose 5. i 6. senzora u ravni $Z-Y$ i pod uglom $58,28^{\circ}$ u odnosu na $Y$ osu, matrice $\mathrm{H}_{2}$ i $V_{2}$ biće (slika 2): ${ }^{6}$

${ }^{6}$ Ovu arhitekturu IMB predložili su J. Gilmore i R. McKern sa Masačusetskog instituta.

$$
H_{2}=\left[\begin{array}{ccc}
0,52573 & 0 & 0,85065 \\
-0,52573 & 0 & 0,85065 \\
0,85065 & 0,52573 & 0 \\
0,85065 & -0,52573 & 0 \\
0 & 0,85065 & 0,52573 \\
0 & 0,85065 & -0,52573
\end{array}\right]
$$

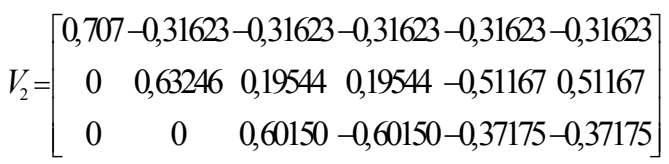

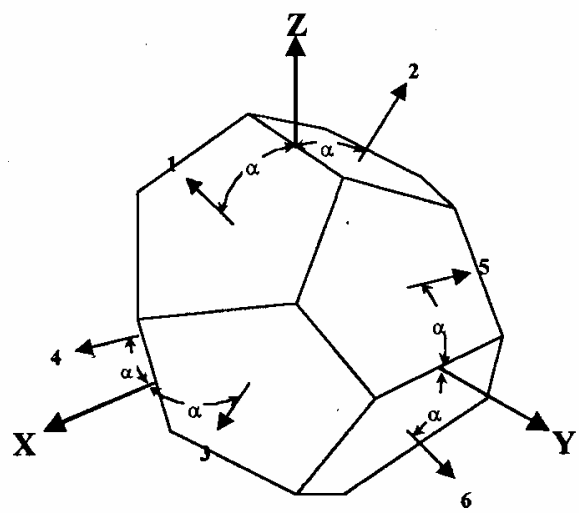

Sl. 2 - Druga varijanta arhitektura IMB u obliku pravilnog dodekaedra

Na slici 3 prikazan je pravilni oktaedar u kojem komplementarne ose senzora (1 i 2,3 i 4 i 5 i 6) čine ugao od $90^{\circ}$, jedne sa drugom, i simetrične su u odnosu na ose aviona. Senzori 1 i 2 nagnuti su $45^{\circ} \mathrm{u}$ odnosu na $\mathrm{Z}$ osu aviona, senzori $3 \mathrm{i}$ 4 pomereni su za $45^{\circ}$ u odnosu na $X$ osu aviona, a senzori 5 i 6 pomereni su za $45^{\circ}$ u odnosu na $Y$ osu aviona. Ovi senzori su ujedno ortogonalni u odnosu na ivice oktaedra. Za ovaj slučaj matrice $\mathrm{H}_{3}$ i $V_{3}$ imaju vrednosti: ${ }^{7}$ 

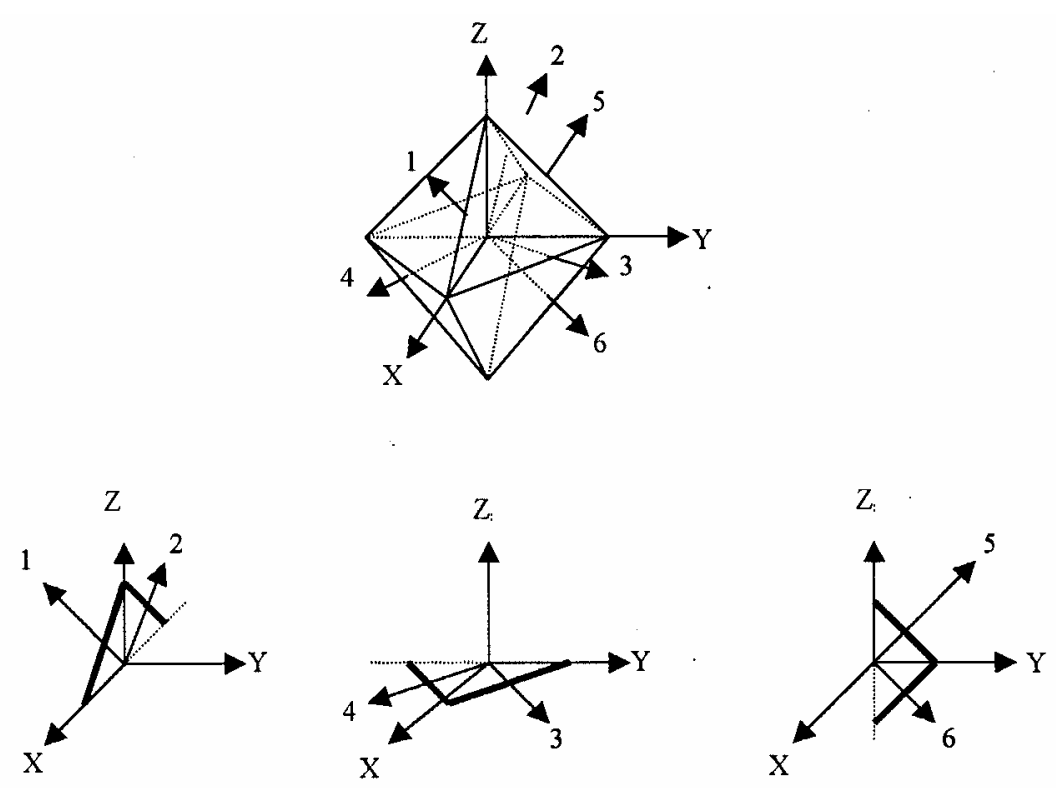

Sl. 3 - Razmeštaj senzora po oktaedru

$$
\begin{aligned}
& H_{3}=\left[\begin{array}{ccc}
\cos 45^{\circ} & 0 & \cos 45^{\circ} \\
-\cos 45^{\circ} & 0 & \cos 45^{\circ} \\
\cos 45^{\circ} & \cos 45^{\circ} & 0 \\
\cos 45^{\circ} & -\cos 45^{\circ} & 0 \\
0 & \cos 45^{\circ} & \cos 45^{\circ} \\
0 & \cos 45^{\circ} & -\cos 45^{\circ}
\end{array}\right]= \\
& =\left[\begin{array}{ccc}
0,707 & 0 & 0,707 \\
-0,707 & 0 & 0,707 \\
0,707 & 0,707 & 0 \\
0,707 & -0,707 & 0 \\
0 & 0,707 & 0,707 \\
0 & 0,707 & -0,707
\end{array}\right] \\
& V_{3}=\left[\begin{array}{cccccc}
0,707 & 0 & -0,354 & -0,354 & -0,354 & 0,354 \\
0 & 0,707 & 0,354 & 0,354 & -0,354 & 0,354 \\
0 & 0 & 0,499 & -0,501 & -0,501 & -0,501
\end{array}\right]
\end{aligned}
$$

U slučaju ortogonalne arhitekture IMB sa tri SDOF senzora, kod koje su merne ose senzora međusobno ortogonalne i usmerene u pravcu osa aviona, matrice $\mathrm{H}_{4}$ i $V_{4}$ imaju vrednost:

$$
H_{4}=\left[\begin{array}{lll}
1 & 0 & 0 \\
0 & 1 & 0 \\
0 & 0 & 1
\end{array}\right] \quad V_{4}=\left[\begin{array}{lll}
1 & 0 & 0 \\
0 & 1 & 0 \\
0 & 0 & 1
\end{array}\right]
$$

U slučaju konusne arhitekture (slika 4) IMB sa četiri SDOF senzora, sve merne ose senzora su u ravni konusa, pri čemu su merne ose SDOF senzora u pravcu avionskih osa i međusobno obrazuju konus pod uglom od $54,75^{\circ}=\arccos$ $\left(\frac{1}{\sqrt{3}}\right)$, matrice $H_{5}$ i $V_{5}$ imaju vrednost ${ }^{8}$ :

${ }^{8}$ Dato u [2]. 

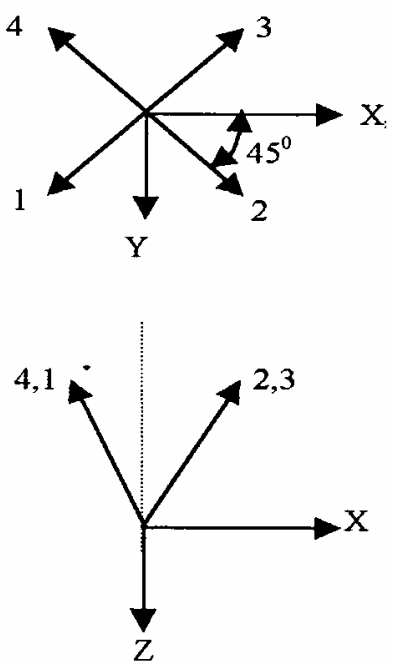

Sl. 4 - Arhitektura IMB u obliku tetrade

$$
\begin{aligned}
& H_{5}=\frac{1}{\sqrt{3}} \cdot\left[\begin{array}{ccc}
-1 & 1 & -1 \\
1 & 1 & -1 \\
1 & -1 & -1 \\
-1 & -1 & -1
\end{array}\right] \\
& V_{5}=\left[\begin{array}{cccc}
1 & -1 & 1 & -1 \\
-1 & 1 & -1 & 1 \\
1 & -1 & 1 & -1 \\
-1 & 1 & -1 & 1
\end{array}\right]
\end{aligned}
$$

Za slučaj na slici 5 , matrice $H_{6}$ i $V_{6}$ imaju vrednost':

$$
\begin{aligned}
& H_{6}=\frac{1}{\sqrt{3}} \cdot\left[\begin{array}{ccc}
0 & \sqrt{2} & -1 \\
\sqrt{2} & 0 & -1 \\
0 & -\sqrt{2} & -1 \\
-\sqrt{2} & 0 & -1
\end{array}\right] \\
& V_{6}=\left[\begin{array}{cccc}
1 & -1 & 1 & -1 \\
-1 & 1 & -1 & 1 \\
1 & -1 & 1 & -1 \\
-1 & 1 & -1 & 1
\end{array}\right] \\
& { }^{9} \text { Dato u }[3] .
\end{aligned}
$$
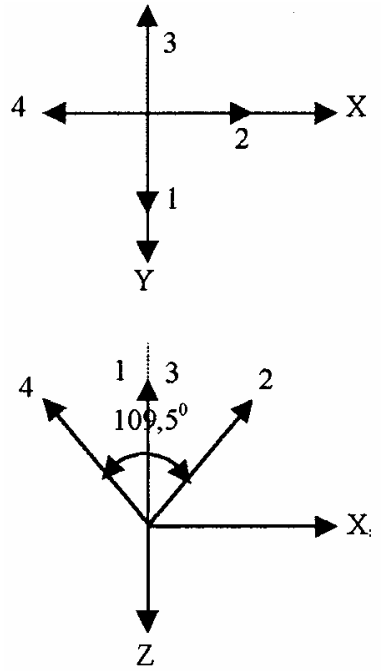

Sl. 5 - Druga varijanta arhitekture IMB u obliku tetrade

U slučaju konusne arhitekture IMB sa pet SDOF senzora, čije su merne ose razmeštene oko konusa, čiji je centralni ugao $109,5^{\circ}$ (slika 6), matrice $H_{7}$ i $V_{7}$ imaju vrednost ${ }^{10}$ :

$H_{7}=\left[\begin{array}{ccc}0,97204 & 0 & -0,23482 \\ -0,60075 & -0,77653 & -0,18997 \\ 0 & 0,47992 & 0,87731 \\ 0 & -0,47992 & 0,87731 \\ -0,60075 & 0,77653 & -0,18997\end{array}\right]$

$V_{7}=\left[\begin{array}{ccccc}0,63245 & 0,51167 & 0,19543 & 0,19543 & 0,51167 \\ 0 & 0,37175 & 0,60150 & -0,60150 & -0,37175\end{array}\right]$

U slučaju arhitekture IMB sa osam SDOF senzora, čije merne ose čine ugao od $45^{\circ}$ sa jednom od ivica osnove oktaedra, matrice $H_{8}$ i $V_{8}$ imaju vrednost ${ }^{11}$ :

\footnotetext{
${ }^{10}$ Konusna arhitektura IMB koju je predložila firma Hamilton Standard, Division of United Technologies.

${ }^{11}$ Arhitekturu u obliku oktaedra prva je predložila, izradila i ispitala firma Teledyne Systems Comp.
} 


$$
H_{8}=\left[\begin{array}{ccc}
0,70711 & -0,40825 & 0,57735 \\
0,70711 & 0,40825 & -0,57735 \\
0,40825 & 0,70711 & 0,57735 \\
-0,40825 & 0,70711 & -0,57735 \\
-0,70711 & 0,40825 & 0,57735 \\
-0,70711 & -0,40825 & -0,57735 \\
-0,40825 & -0,70711 & 0,57735 \\
0,40825 & -0,70711 & -0,57735
\end{array}\right]
$$

$$
V_{8}=\left[\begin{array}{cccccccc}
0,79057 & 0 & -0,15811 & 0,43198 & 0,15811 & 0,31623 & -0,15811 & -0,158 \\
0 & 0,79057 & -0,11575 & -0,15811 & 0,31623 & 0,15811 & 0,43198 & -0,158 \\
0 & 0 & 0,76590 & 0,06528 & -0,08278 & 0,53507 & 0,19585 & 0,278 \\
0 & 0 & 0 & 0,63964 & -0,16322 & -0,42451 & 0,58442 & 0,206 \\
0 & 0 & 0 & 0 & 0,68301 & -0,18301 & -0,18301 & 0,693
\end{array}\right]
$$

\section{Arhitekture IMB sa TDOF senzorima}

Razmatraju se sledeće arhitekture IMB: simetrična, ortogonalna i koplanarna.

Simetrična arhitektura IMB sa TDOF senzorima ima osobinu da je apsolutna

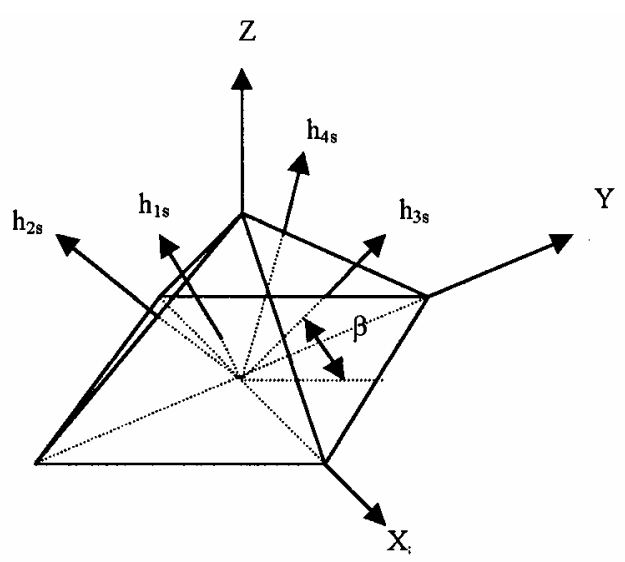

Sl. 7 - Simetrična arhitektura IMB sa TDOF senzorima

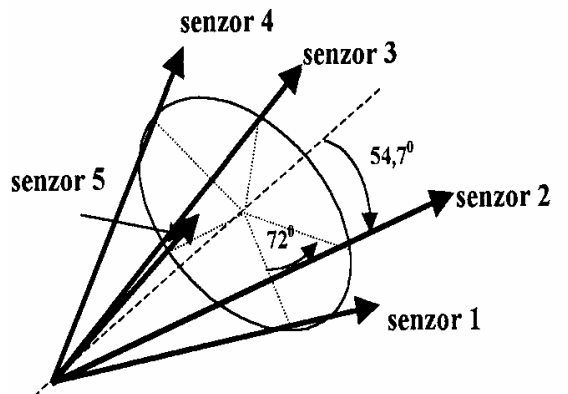

Sl. 6 - Konusna arhitektura IMB sa pet SDOF senzora

vrednost skalarnog proizvoda dva različita vektora spin osa senzora konstantna, $\mathrm{t} \mathrm{j}$.:

$\left|\vec{h}_{i s} \cdot \vec{h}_{j s}\right|=K, \exists i, j, i \neq j$

gde je:

$h_{i s}$ - vektor $i$-te spin ose TDOF senzora, $K$ - konstanta i za IMB sa TDOF senzorima usmerenih na stranice pravilnog poluoktaedra (slika 7) iznosi $K=\frac{1}{2}$, a za IMB sa TDOF senzorima usmerenih na stranice pravilnog dodekaedra je $K=\frac{1}{\sqrt{5}}$.

U slučaju četiri TDOF senzora, gde osam mernih osa i četiri spin ose (normalne na stranice oktaedra) leže na površini konusa sa uglom $\arccos (-K), K$ je dato u (44): 
$H_{9}^{T}=\frac{1}{2 \sqrt{3}}\left[\begin{array}{cccccccc}\sqrt{3+1} & -\sqrt{3+1} & \sqrt{3-1} & -\sqrt{3-1} & -\sqrt{3-1} & \sqrt{3-1} & -\sqrt{3+1} & \sqrt{3+1} \\ -\sqrt{3+1} & \sqrt{3+1} & \sqrt{3+1} & -\sqrt{3+1} & \sqrt{3-1} & -\sqrt{3-1} & -\sqrt{3-1} & \sqrt{3-1} \\ 2 & 2 & 2 & 2 & 2 & 2 & 2 & 2\end{array}\right]$

Tada je: $V_{9}=\left[\begin{array}{cccccccc}0,183 & 0,683 & -0,683 & -0,183 & 0 & 0 & 0 & 0 \\ 0,5 & -0,5 & 0 & 0 & 0,5 & -0,5 & 0 & 0 \\ 0 & 0 & 0,5 & -0,5 & 0 & 0 & 0,5 & -0,5\end{array}\right]$

U slučaju ortogonalne arhitekture IMB sa TDOF senzorima neke spin ose senzora moraju biti međusobno normalne. Kod ortogonalne arhitekture IMB sa četiri TDOF senzora, prikazanih na slici 8 , tri spin ose $\vec{h}_{2 s}, \vec{h}_{3 s}, \vec{h}_{4 s}$ su međusobno ortogonalne, a četvrta spin $\vec{h}_{1 s}$ osa leži u ravni koja je definisana sa dve $\left(\vec{h}_{3 s}, \vec{h}_{4 s}\right)$ od preostale tri ose i pod uglom od $45^{\circ} \mathrm{u}$ odnosu na avionsku $X$-osu.

Matrice $H_{10}$ i $V_{10}$ tada imaju sledeće vrednosti:

$$
V_{10}=\left[\begin{array}{cccccccc}
0,707 & 0 & -0,707 & 0 & 0 & 0 & 0 & 0 \\
0,707 & 0 & 0 & 0 & -0,707 & 0 & 0 & 0 \\
0 & 0 & 0 & 0 & 0 & -0,707 & 0 & 0,707 \\
0 & 0 & 0 & -0,707 & 0 & 0 & 0,707 & 0 \\
0 & 0,707 & 0 & 0,5 & 0 & 0 & 0 & 0,5
\end{array}\right]
$$

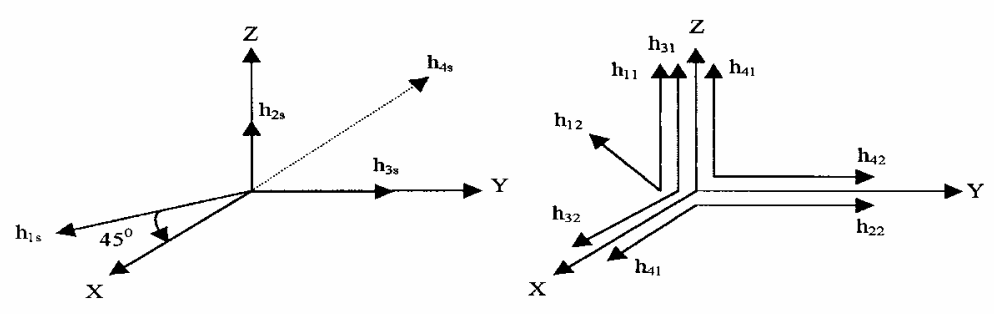

Sl. 8 - Ortogonalna arhitektura sa TDOF senzorima

Za ortogonalnu arhitekturu, kod koje su najmanje tri spin ose senzora međusobno ortogonalne, potrebno je formirati najmanje pet jednačina parnosti, $i$ to: dve za detekciju i izolaciju otkaza, tri koline- arna senzora i tri za detekciju i izolaciju otkaza koplanarnih senzora.

Kod koplanarne arhitekture IMB sa četiri TDOF senzora sve četiri spin ose TDOF senzora moraju da leže u jednoj 
ravni, a osam mernih osa je simetrično ugao konusa $90^{\circ}$ (slika 9). Tada matrice razmešteno po površini konusa, čiji je $H_{11}$ i $V_{11}$ imaju vrednost:

$$
\begin{aligned}
H_{11}^{T} & =\left[\begin{array}{cccccccc}
-\frac{1}{\sqrt{2}} & \frac{1}{\sqrt{2}} & 0 & 0 & -\frac{1}{2} & \frac{1}{2} & \frac{1}{2} & \frac{1}{2} \\
0 & 0 & \frac{1}{\sqrt{2}} & -\frac{1}{\sqrt{2}} & \frac{1}{2} & -\frac{1}{2} & \frac{1}{2} & -\frac{1}{2} \\
\frac{1}{\sqrt{2}} & \frac{1}{\sqrt{2}} & \frac{1}{\sqrt{2}} & \frac{1}{\sqrt{2}} & \frac{1}{\sqrt{2}} & \frac{1}{\sqrt{2}} & \frac{1}{\sqrt{2}} & \frac{1}{\sqrt{2}}
\end{array}\right] \\
V_{11} & =\left[\begin{array}{ccccccccc}
0,5 & 0,5 & -0,5 & -0,5 & 0 & 0 & 0 & 0 \\
0,5 & 0,5 & 0 & 0 & -0,5 & -0,5 & 0 & 0 \\
0,5 & 0,5 & 0 & 0 & 0 & 0 & -0,5 & -0,5
\end{array}\right]
\end{aligned}
$$

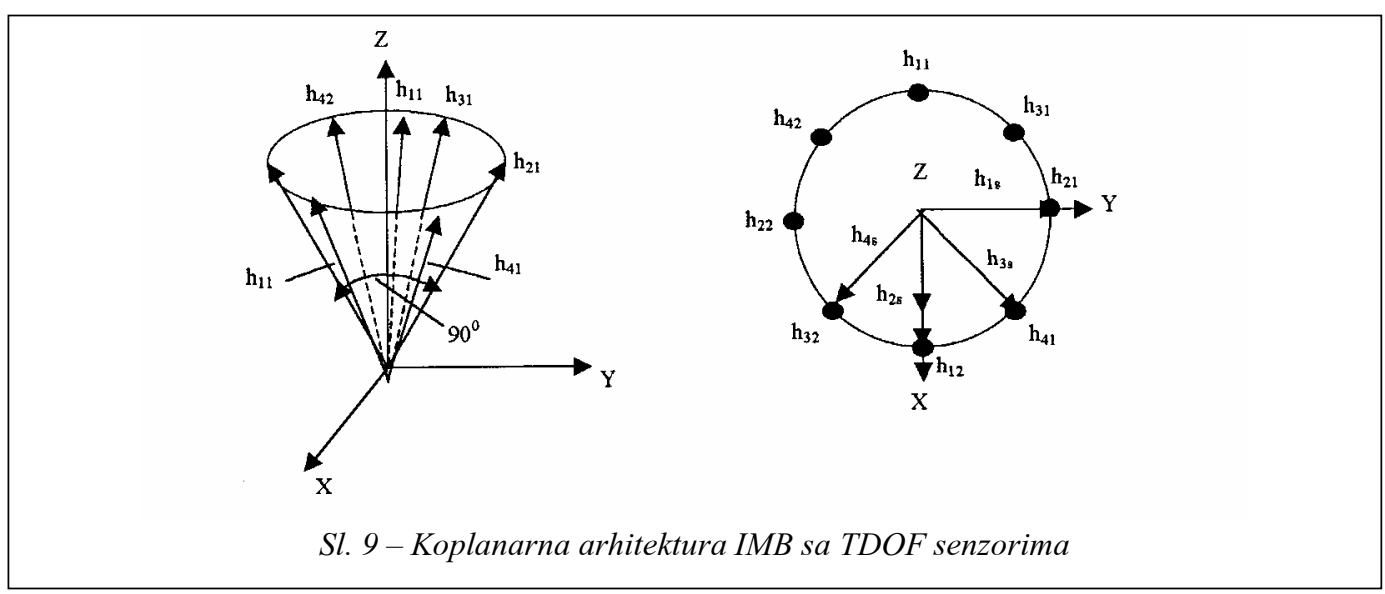

\section{Uporedna analiza arhitektura inercijalnog mernog bloka}

Primena algoritma sa $n$ jednačina parnosti u izračunavanju koeficijenata matrice $V$ i koeficijenata $J_{i}^{T}$ i $F_{d 2}$ na arhitekture IMB sa matricama $H_{9}, H_{10}$ i $H_{11}$ prikazana je u tabelama 1,2 i 3 . U tabeli 1 prikazane su vrednosti za koeficijente $J_{i}$ samo za jednačinu parnosti $p_{8}$. I za jednačine parnosti $p_{1} \div p_{7}$ (tabela 1$)$ može se pokazati da je $F_{d 2}=3,3$, jer su iste vred- nosti koeficijenata $J_{j}$ samo u izmenjenom redu.

Pošto je, prema (42), vrednost $F_{d 2}$ najmanja za jednačinu parnosti $p_{3}$ i iznosi 1,8 (tabela 2), ta vrednost predstavlja vrednost pokazatelja kvaliteta za ortogonalnu arhitekturu $H_{7}$.

I za jednačine parnosti $p_{1} \div p_{7}$ može se pokazati da je $F_{d 2}=3,7$, jer su iste vrednosti koeficijenata $J_{j}$ (tabela 3 ), samo u izmenjenom redu. 
Vrednosti koeficijenata $V i J_{j}$ za arhitekturu IMB $H_{9}$

\begin{tabular}{|c|c|c|c|c|c|c|c|c|c|}
\hline \multirow{2}{*}{\multicolumn{2}{|c|}{$\begin{array}{c}\text { Arhitektura } \mathrm{H}_{9} \\
\text { Jednačine } \\
\text { parnosti, } \mathrm{p}_{\mathrm{i}}\end{array}$}} & \multirow{2}{*}{\multicolumn{8}{|c|}{ Koeficijenti matrice $\mathrm{V}$}} \\
\hline & & & & & & & & & \\
\hline \multicolumn{2}{|c|}{$\mathrm{p}_{1}$} & 1 & 0 & $-0,2$ & 0,1464 & 0,2 & $-0,4$ & $-0,2$ & 0,5464 \\
\hline \multicolumn{2}{|c|}{$\mathrm{p}_{2}$} & 0 & 1 & $-0,5464$ & $-0,2$ & $-0,4$ & 0,2 & 0,1464 & $-0,2$ \\
\hline \multicolumn{2}{|c|}{$\mathrm{p}_{3}$} & $-0,2$ & $-0,5464$ & 1 & 0 & $-0,2$ & 0,1464 & 0,2 & $-0,4$ \\
\hline \multicolumn{2}{|c|}{$\mathrm{p}_{4}$} & 0,1464 & $-0,2$ & 0 & 1 & $-0,5464$ & $-0,2$ & $-0,4$ & 0,2 \\
\hline \multicolumn{2}{|c|}{$\mathrm{p}_{5}$} & 0,2 & $-0,4$ & $-0,2$ & $-0,5464$ & 1 & 0 & $-0,2$ & 0,1464 \\
\hline \multicolumn{2}{|c|}{$\mathrm{p}_{6}$} & $-0,4$ & 0,2 & 0,1464 & $-0,2$ & 0 & 1 & $-0,5464$ & $-0,2$ \\
\hline \multicolumn{2}{|c|}{$\mathrm{p}_{7}$} & $-0,2$ & 0,1464 & 0,2 & $-0,4$ & $-0,2$ & $-0,5464$ & 1 & 0 \\
\hline \multicolumn{2}{|c|}{$\mathrm{p}_{8}$} & $-0,5464$ & $-0,2$ & $-0,4$ & 0,2 & 0,1464 & $-0,2$ & 0 & 1 \\
\hline \multirow{2}{*}{$\begin{array}{c}\begin{array}{c}\text { Jednačina } \\
\text { parnosti }\end{array} \\
\end{array}$} & & \multicolumn{8}{|c|}{ Koeficijenti $J_{i}$} \\
\hline & $\mathrm{F}_{\mathrm{d} 2}$ & $\mathrm{~J}_{1}$ & $\mathrm{~J}_{2}$ & $\mathrm{~J}_{3}$ & $\mathrm{~J}_{4}$ & $\mathrm{~J}_{5}$ & $\mathrm{~J}_{6}$ & $\mathrm{~J}_{7}$ & $\mathrm{~J}_{8}$ \\
\hline $\mathrm{p}_{8}$ & 3,3 & 0,187 & 0,025 & 0,1 & 0,025 & 0,013 & 0,025 & 0 & 0,625 \\
\hline
\end{tabular}

Vrednosti koeficijenata $V$ i $J_{j}$ za arhitekturu IMB $H_{10}$

Tabela 2

\begin{tabular}{|c|c|c|c|c|c|c|c|c|c|}
\hline \multirow{2}{*}{\multicolumn{2}{|c|}{$\begin{array}{c}\text { Arhitektura } \mathrm{H}_{10} \\
\text { Jednačine } \\
\text { parnosti, } \mathrm{p}_{\mathrm{i}}\end{array}$}} & \multirow{2}{*}{\multicolumn{8}{|c|}{ Koeficijenti matrice $\mathrm{V}$}} \\
\hline & & & & & & & & & \\
\hline \multicolumn{2}{|c|}{$\mathrm{p}_{1}$} & 1 & 0 & 0 & 0 & $-0,5$ & 0 & $-0,5$ & 0 \\
\hline \multicolumn{2}{|c|}{$p_{2}$} & 0 & 1 & $-0,3536$ & 0,3536 & 0 & 0,3536 & 0 & 0,3536 \\
\hline \multicolumn{2}{|c|}{$\mathrm{p}_{3}$} & 0 & 0,3536 & 1 & 0 & 0 & $-0,75$ & 0 & 0,25 \\
\hline \multicolumn{2}{|c|}{$\mathrm{p}_{4}$} & 0 & 0,3536 & 0 & 1 & 0 & 0,25 & 0 & $-0,75$ \\
\hline \multicolumn{2}{|l|}{$\mathrm{p}_{5}$} & $-0,5$ & 0 & 0 & 0 & 1 & 0 & $-0,5$ & 0 \\
\hline \multicolumn{2}{|c|}{$\mathrm{p}_{6}$} & 0 & 0,4041 & $\begin{array}{l}-0,7143 \\
\end{array}$ & 0,1523 & 0 & 1 & 0 & 0,1428 \\
\hline \multicolumn{2}{|c|}{$\mathrm{p}_{7}$} & $-0,5$ & 0 & 0 & 0 & $-0,5$ & 0 & 1 & 0 \\
\hline \multicolumn{2}{|c|}{$\mathrm{p}_{8}$} & 0 & 0,4041 & 0,1428 & $-0,7143$ & 0 & 0,1428 & 0 & 1 \\
\hline \multirow{2}{*}{$\begin{array}{l}\text { Jednačina } \\
\text { parnosti }\end{array}$} & & \multicolumn{8}{|c|}{ Koeficijenti $\mathrm{J}_{\mathrm{i}}$} \\
\hline & $\mathrm{F}_{\mathrm{d} 2}$ & $\mathrm{~J}_{1}$ & $\mathrm{~J}_{2}$ & $\mathrm{~J}_{3}$ & $\mathrm{~J}_{4}$ & $J_{5}$ & $J_{6}$ & $\mathrm{~J}_{7}$ & $\mathrm{~J}_{8}$ \\
\hline $\mathrm{p}_{1}$ & 4,0 & 0,667 & 0 & 0 & 0 & 0,167 & 0 & 0,167 & 0 \\
\hline $\mathrm{p}_{2}$ & 8,0 & 0 & 0,667 & 0,083 & 0,083 & 0 & 0,083 & 0 & 0,083 \\
\hline$p_{3}$ & 1,8 & 0 & 0,071 & 0,57 & 0 & 0 & 0,32 & 0 & 0,036 \\
\hline $\mathrm{p}_{7}$ & 4,0 & 0,167 & 0 & 0 & 0 & 0,167 & 0 & 0,667 & 0 \\
\hline $\mathrm{p}_{8}$ & 2,0 & 0 & 0,095 & 0,012 & 0,0298 & 0 & 0,012 & 0 & 0,0583 \\
\hline
\end{tabular}

Vrednosti koeficijenata $V i J_{j}$ za arhitekturu IMB $H_{l 1}$

Tabela 3

\begin{tabular}{|c|c|c|c|c|c|c|c|c|c|}
\hline \multirow{2}{*}{\multicolumn{2}{|c|}{$\begin{array}{c}\text { Arhitektura } \mathrm{H}_{11} \\
\text { Jednačine } \\
\text { parnosti, } \mathrm{p}_{\mathrm{i}}\end{array}$}} & \multirow{2}{*}{\multicolumn{8}{|c|}{ Koeficijenti matrice $\mathrm{V}$}} \\
\hline & & & & & & & & & \\
\hline \multicolumn{2}{|c|}{$\mathrm{p}_{1}$} & 1 & 0 & $-0,1667$ & $-0,1667$ & $-0,5202$ & 0,1869 & 0,1869 & $-0,5202$ \\
\hline \multicolumn{2}{|c|}{$\mathrm{p}_{2}$} & 0 & 1 & $-0,1667$ & $-0,1667$ & 0,1869 & $-0,5202$ & $-0,5202$ & 0,1869 \\
\hline \multicolumn{2}{|c|}{$\mathrm{p}_{3}$} & $-0,1667$ & $-0,1667$ & 1 & 0 & $-0,5202$ & 0,1869 & $-0,5202$ & 0,1869 \\
\hline \multicolumn{2}{|c|}{$\mathrm{p}_{4}$} & $-0,1667$ & $-0,1667$ & 0 & 1 & 0,1869 & $-0,5202$ & 0,1869 & $-0,5202$ \\
\hline \multicolumn{2}{|c|}{$\mathrm{p}_{5}$} & $-0,5202$ & 0,1869 & $-0,5202$ & 0,1869 & 1 & 0 & $-0,1667$ & $-0,1667$ \\
\hline \multicolumn{2}{|c|}{$\mathrm{p}_{6}$} & 0,1869 & $-0,5202$ & 0,1869 & $-0,5202$ & 0 & 1 & $-0,1667$ & $-0,1667$ \\
\hline \multicolumn{2}{|c|}{$\mathrm{p}_{7}$} & 0,1869 & $-0,5202$ & $-0,5202$ & 0,1869 & $-0,1667$ & $-0,1667$ & 1 & 0 \\
\hline \multicolumn{2}{|c|}{$\mathrm{p}_{8}$} & $-0,5202$ & 0,1869 & 0,1869 & $-0,5202$ & $-0,1667$ & $-0,1667$ & 0 & 1 \\
\hline \multirow{3}{*}{$\begin{array}{c}\begin{array}{c}\text { Jednačina } \\
\text { parnosti }\end{array} \\
p_{0}\end{array}$} & $\mathrm{~F}_{\mathrm{d}}$ & \multicolumn{8}{|c|}{ Koeficijenti $\mathrm{J}_{\mathrm{i}}$} \\
\hline & $\mathrm{F}_{\mathrm{d} 2}$ & $\mathrm{~J}_{1}$ & $\mathrm{~J}_{2}$ & $\mathrm{~J}_{3}$ & $\mathrm{~J}_{4}$ & $\mathrm{~J}_{5}$ & $\mathrm{~J}_{6}$ & $\mathrm{~J}_{7}$ & $\mathrm{~J}_{8}$ \\
\hline & 3,7 & 0,162 & 0,021 & 0,021 & 0,162 & 0,017 & 0,017 & 0 & 0,6 \\
\hline
\end{tabular}




\section{Zaključak}

U ovom članku izložen je algoritam određivanja brojčanog pokazatelja kvaliteta proizvoljne arhitekture IMB, sa stanovišta pogodnosti za detekciju i izolaciju neispravnog senzora IMB.

$\mathrm{Na}$ osnovu analize vrednosti brojčanih pokazatelja arhitektura $H_{1} \div H_{11}$ IMB, koje su date u literaturi ili se nalaze $\mathrm{u}$ proizvodnim programima mnogih svet- skih proizvođača INS, najbolja svojstva za primenu ima koplanarna arhitektura $H_{11}$, ukoliko se koristi osam jednačina parnosti, a arhitekture $H_{1}$ i $H_{2}$ u slučaju da algoritam FDI koristi minimalan broj jednačina parnosti (tabela 4). Ortogonalne arhitekture su prihvatljive samo u slučaju korišćenja minimalnog broja jednačina parnosti. Predloženi algoritam može se primeniti pri analizi i drugog skupa proizvoljnih arhitektura IMB.

Tabela 4

Vrednosti pokazatelja kvaliteta arhitektura IMB sa stanovišta pogodnosti za detekciju neispravnih senzora

\begin{tabular}{|c|c|c|c|}
\hline Arhitektura IMB & Varijanta, matrica $\mathrm{H}_{\mathrm{i}}$ & $\begin{array}{l}\text { Pokazatelj kvaliteta } \\
\text { arhitekture, } \mathrm{F}_{\mathrm{d} 2}\end{array}$ & Rang, $F_{\text {naj }}$ \\
\hline \multirow{8}{*}{$\begin{array}{l}\text { Sa SDOF } \\
\text { senzorima }\end{array}$} & $6 \mathrm{SDOF}, \mathrm{H}_{1}$ & 5,0 & 1 \\
\hline & $6 \mathrm{SDOF}, \mathrm{H}_{2}$ & 5,0 & 1 \\
\hline & $6 \mathrm{SDOF}, \mathrm{H}_{3}$ & 4,0 & 2 \\
\hline & $3 \mathrm{SDOF}, \mathrm{H}_{4}$ & 0 & 8 \\
\hline & $4 \mathrm{SDOF}, \mathrm{H}_{5}$ & 1 & 7 \\
\hline & $4 \mathrm{SDOF}, \mathrm{H}_{6}$ & 1 & 7 \\
\hline & $5 \mathrm{SDOF}, \mathrm{H}_{7}$ & 1,52 & 6 \\
\hline & $8 \mathrm{SDOF}, \mathrm{H}_{8}$ & 3,36 & 4 \\
\hline \multirow{3}{*}{$\begin{array}{l}\text { Sa TDOF } \\
\text { senzorima }\end{array}$} & $\begin{array}{r}\text { Simetrična } \\
4 \text { TDOF, } H_{9} \\
\end{array}$ & 3,3 & 4 \\
\hline & $\begin{array}{l}\text { Ortogonalna } \\
4 \mathrm{TDOF}, \mathrm{H}_{10}\end{array}$ & 1,8 & 5 \\
\hline & $\begin{array}{c}\text { Koplanarna } \\
4 \text { TDOF, } \mathrm{H}_{11}\end{array}$ & 3,7 & 3 \\
\hline
\end{tabular}

\section{Literatura:}

[1] Potter, E.; Suman, C.: Thresholdless redundancy management with arrays of skewed instruments, AGARD-224, Control Systems, 1977, 15-1 do 15-25.

[2] Daly, K.; Gai, E.; Harrison, J.: Generalized Likelihood Test for FDI in Redundant Sensor Configurations, J. Guidance and Control, Vol. 2, No. 1, Jan.-Feb. 1979.

[3] Gai, E.; Harrison, J.; Daly, K.: FDI Performance of Two Redundant Sensor Configurations, IEEE Transaction on AES, Vol. AES-15, №3, Nov. 1979.
[4] Satin, A.; Gates, R.: Evaluation of Parity Equations for Gyro Failure Detection and Isolation, AIAA J. Guidance and Control, Vol. 2, Nº1, Jan.-Feb. 1978.

[5] Mitrinović, D. S.; Mihajlović, D.; Vasić, P. M.: Linearna algebra, Polinomi, Analitička geometrija, Građevinska knjiga, Beograd, 1973.

[6] Бронштейн, И. Х.; Семендяев, К. А.: Справочник по математике, Наука, Москва, 1986.

[7] Janićijević, S.: Model određivanja optimalne arhitekture inercijalnog mernog bloka, doktorska desertacija, VA, novembar 2003. godine. 
